\title{
Tsafon
}

Revue d'études juives du Nord

$77 \mid 2019$

Contribution à l'histoire des traductions juives de la Bible hébraïque

\section{Des Tsiganes vers Auschwitz. Le convoi Z du 15 janvier 1944}

\section{Danielle Delmaire}

\section{(2) OpenEdition}

\section{Journals}

Édition électronique

URL : https://journals.openedition.org/tsafon/2153

DOI : $10.4000 /$ tsafon. 2153

ISSN : 2609-6420

Éditeur

Association Jean-Marie Delmaire

Édition imprimée

Date de publication : 1 septembre 2019

Pagination : 177-179

ISSN : $1149-6630$

Référence électronique

Danielle Delmaire, «Des Tsiganes vers Auschwitz. Le convoi Z du 15 janvier 1944 », Tsafon [En ligne], 77 | 2019, mis en ligne le 09 septembre 2019, consulté le 24 juin 2021. URL : http:// journals.openedition.org/tsafon/2153; DOI : https://doi.org/10.4000/tsafon.2153

Ce document a été généré automatiquement le 24 juin 2021

Tsafon. Revues d'études juives du Nord 


\title{
Des Tsiganes vers Auschwitz. Le convoi Z du 15 janvier 1944
}

\author{
Danielle Delmaire
}

\section{RÉFÉRENCE}

Paris, éd. Tirésias, 323 p., $27 €$.

1 Les Tsiganes résidant dans les départements du Nord et du Pas-de-Calais furent les seuls, en France, à être déportés. Comme les juifs des mêmes départements, ils furent internés à la caserne Dossin de Malines (Belgique), camp de transit avant la déportation vers Auschwitz. Sur 351 personnes constituant ce convoi, $90 \%$ d'entre eux ne revinrent pas. C'est à l'histoire d'un convoi particulier, le convoi Z du 15 janvier 1944, que Monique Heddebaut s'est intéressée pour un master en histoire. Cette recherche excellente et des compléments d'information ont abouti à cet ouvrage. L'auteure est désormais reconnue parmi les spécialistes de la déportation des Tsiganes et du sort de ces derniers dans les camps d'internement en France, durant la Seconde Guerre mondiale. À ce titre, elle a été sollicitée par le Mémorial de la Shoah pour monter, avec d'autres historiens, l'exposition sur les Tsiganes pendant la guerre. Elle avait déjà présenté une partie des ses recherches dans un $n^{\circ}$ hors-série de Tsafon, paru en 2008 .

2 La mise à l'écart des Tsiganes dans la société française ne date pas de la Seconde Guerre mondiale. Monique Heddebaut le rappelle avant même d'entamer l'histoire du convoi Z (comme Zigeuners). Depuis bien longtemps, leur vie nomade les rendait suspects et ils étaient des " étrangers de l'intérieur ». Une législation anti-tsigane avait été mise en place par la Troisième République. Puis, établis dans les départements du nord de la France rattachés au commandement militaire de Bruxelles dès 1940, ils subirent, tous comme les juifs vivant dans ces mêmes départements, la législation raciale allemande.

C'est à l'automne 1943 que la tragédie commença. Les Tsiganes furent raflés dans leurs campements, sans ménagement. Leurs biens furent confisqués, ils furent spoliés 
comme les juifs. La population avoisinante se désola mais personne ne vint en aide à cette population marginalisée depuis longtemps.

4 La vie quotidienne à la caserne Dossin était faite d'humiliation, de vexation et de maltraitance qui attiraient la pitié des autres internés. Les familles étaient regroupées et les enfants nombreux, il y eut même une naissance à Malines.

5 Le convoi $Z$ fut acheminé vers Auschwitz. Les femmes y subirent, outre la faim et les maladies, les traitements de stérilisation qui devaient mettre fin à l'existence des Tsiganes : il s'agissait bien d'une "solution finale " et planifiée elle aussi, selon l'auteure. Après quelques mois passés à Auschwitz, des hommes furent transférés à Dora et à Buchenwald où la place manquait, ils survécurent donc sous des tentes. Des femmes furent transférées à Ravensbrück. Les conditions de vie y étaient tout aussi meurtrières et plusieurs Tsiganes y perdirent la vie.

6 L'accueil au retour des camps, tant de la part de la population que de celle des services chargés de leur venir en aide, ne fut pas à la hauteur des sévices subis. Certes, les rescapés de la déportation raciale furent hospitalisés mais les déportés politiques attiraient toute l'attention des secours, les déportés tsiganes (juifs également) étaient moins honorés, dépourvus de l'auréole de la Résistance ! Et les Tsiganes plus particulièrement n'intéressaient pas grand monde. Après la guerre, une législation restrictive avait toujours cours. Faire reconnaitre la spoliation d'une roulotte n'était pas facile. Délaissés, les Tsiganes ont replongé dans la mise à l'écart et la stigmatisation maintenues après la guerre.

7 Monique Heddebaut a travaillé scrupuleusement dans les centres d'archives en Allemagne, en Belgique et en France où elle a pu découvrir des sources encore inexploitées. Ce qui lui a permis de reconstituer la liste des 351 déportés du convoi $\mathrm{Z}$ qu'elle reproduit, en fin d'ouvrage. Cette liste est un mémorial comme le sont les deux monuments, sur les lieux des rafles, dont Monique Heddebaut donne la photographie ainsi que la plaque à l'entrée de la caserne Dossin, plaque qui fut apposée après celle rappelant l'internement et la déportation des juifs. 34 déportés revinrent des camps : 21 hommes et 13 femmes qui furent moins nombreuses à survivre ; parmi eux, 3 garçons et 3 filles âgés de moins de 15 ans à leur départ de Malines. Monique Heddebaut donne aussi les noms de ces survivants. Elle a encore retrouvé deux rescapés, Joséphine et Antoine Lagrené, âgés respectivement de 14 et 13 ans à leur départ de Malines et seuls survivants de leur famille d'une trentaine de personnes, qui ont accepté de témoigner. Leurs récits ont apporté d'importants compléments au contenu des archives : les expériences pseudo-médicales subies par Joséphine, les ruses de l'enfant Antoine à Buchenwald. Monique Heddebaut livre là des témoignages inédits.

8 En outre l'auteure pose, en fin d'ouvrage, les questions pertinentes de vocabulaire : distinguer extermination et génocide, pillage et spoliation.

9 Enfin est ajoutée, en fin de volume, la liste des fonds d'archives interrogés, tant en France (Archives de Caen, archives nationales, archives de plusieurs départements et de différentes municipalités) qu'en Belgique ou en Allemagne ou encore en Pologne. Les témoignages, autres que ceux de Joséphine et Antoine Lagrené, qui ont été recueillis par l'auteur ou mis par écrit après la guerre sont également listés.

10 S'y adjoignent une bibliographie abondante, témoignage de l'ampleur du travail de recherche accompli et une courte filmographie. 